\title{
"VOTO BRONCA" Y SENTIDOS DE LA CIUDADANÍA EN ARGENTINA"
}

\author{
Agustín Horacio Perissé* \\ Universidad Nacional de Mar del Plata, Argentina
}

Resumen: En este trabajo se sostiene que los sentidos de la categoría ciudadanía se van transformando a lo largo del tiempo y en las distintas formaciones sociales. Asimismo se afirma que proponer sentidos de la ciudadanía forma parte de la práctica de todos los actores políticos y sociales. En este orden de ideas se señalan las transformaciones ocurridas en la Argentina de los últimos treinta años y las principales concepciones acerca de la ciudadanía, para terminar con un análisis acerca del fenómeno del "voto bronca" de octubre de 2001 y de los sentidos de la ciudadanía que surgen de los discursos de algunos actores en este marco.

Palabras clave: ciudadanía, sentidos, conflictos

\begin{abstract}
This thesis argues that the meanings of citizenship status have been changing over time and in different social strata. It stipulates that proposing meanings to citizenship is a common practice of political and social actors. This way we're enlightening the changes in Argentina during the last thirty years and the principal conceptions about citizenship, ending with an analysis of the phenomenon called "punishment vote" in October 2001 and the meanings of citizenship that emerge from the speeches from political actors in this framework.
\end{abstract}

Keywords: citizenship, meanings, conflicts

\section{INTRODUCCIÓN}

El presente trabajo se propone analizar la emergencia de sentidos acerca de la ciudadanía en los discursos de algunos actores políticos y sociales de Argentina, en el marco del fenómeno del "voto bronca" de octubre de 2001. Se da cuenta de los roles que se le asignan a los ciudadanos en este contexto y de los conflictos entre las distintas visiones de los actores alrededor de este fenómeno.

En consecuencia, la primera hipótesis que preside este trabajo es que proponer sentidos de la ciudadanía forma parte (por lo menos en las sociedades occidentales) de la práctica de todos los actores políticos y sociales. Por este motivo, se realiza un análisis discursivo, tomando como parámetro las ediciones de los periódicos La Nación y Clarín del mes de octubre de 2001.

Nuestra segunda hipótesis es que, en tanto la ciudadanía es una categoría histórica y variable, existen en toda sociedad que reclame esta idea, conflictos y disputas por establecer el contenido de esta noción. Esto lleva a que debamos ubicarnos en alguna etapa histórica para describir cuáles son los

\footnotetext{
${ }^{1}$ El presente trabajo presenta algunos avances de una investigación más amplia en curso que abarca las distintas disputas en torno a la idea de ciudadanía en Argentina en el marco de la crisis de 2001.
} 
debates y entre qué actores se producen, alrededor del concepto de ciudadanía.

Finalmente se formulan algunas hipótesis referidas a las implicancias que estas formas de entender la ciudadanía pudieron haber tenido en el contexto de la crisis de 2001, en el surgimiento y/o la popularización de otras formas de participación ciudadana más allá del voto.

\section{ACLARACIONES METODOLÓGICAS}

En este trabajo se realiza un análisis discursivo, acerca de los sentidos y/o las posibles implicancias de los conceptos de ciudadanía que aparecen expresados en algunos periódicos de circulación masiva de la República Argentina emitidos por distintos actores políticos y sociales que aparecen y que son identificados en este proceso.

Temporalmente el análisis está circunscripto al mes de octubre de 2001, momento en el cual se produjo el fenómeno del "voto bronca" por el que millones de personas, en las elecciones legislativas de ese año, votaron en blanco, anularon su voto o no votaron. Las razones de este recorte son que consideramos esta coyuntura propicia a la visualización de una disputa entre distintos actores con el objeto de legitimar o deslegitimar determinadas acciones, roles y atributos como propios de un ciudadano.

Con este fin se relevaron las ediciones de la prensa escrita del mes de octubre de 2001, de los matutinos Clarín y la Nación, fundamentalmente porque se trata de los dos diarios de mayor circulación nacional.

Metodológicamente sostenemos que los discursos que se expresan en los medios de comunicación (en este caso la prensa escrita) tienen la doble cualidad de reflejar una determinada manera de pensar la sociedad y, en este caso, de pensar la idea de ciudadanía; y, por otro lado, de comunicar y construir estas mismas maneras de entender la ciudadanía.

En este sentido, Michel Foucault señala que “...en cualquier sociedad, relaciones de poder múltiples atraviesan, caracterizan, constituyen el cuerpo social; y estas relaciones de poder no pueden disociarse, ni establecerse, ni funcionar sin una producción, una acumulación, una circulación, un funcionamiento del discurso. No hay ejercicio de poder posible sin una cierta economía de los discursos de verdad que funcionen en, y partir de esta pareja. Estamos sometidos a la producción de la verdad desde el poder y no podemos ejercitar el poder más que a través de la producción de la verdad."2

Por este motivo, creemos que la dialéctica discursiva forma parte no solo de un ejercicio efectivo del poder, tal como lo entendía Foucault, sino que además forma parte de una disputa entre distintos sectores de poder con el objeto de instalar, defender y/o consolidar una determinada organización de la sociedad. De ahí que resulte tan rico el análisis de los conflictos en el nivel discursivo entre los distintos sentidos de la ciudadanía que proponen los actores políticos y sociales. Sin embargo, este análisis acerca del contenido de esta noción no

\footnotetext{
${ }^{2}$ (1992) FOUCAULT, Michel, Microfísica del poder, Editorial La piqueta, Madrid. Pág. 147-148.
} 
puede dejar de ser fragmentario y necesita completarse estableciendo relaciones más profundas entre estos sentidos de la ciudadanía con la posición de poder que ocupan, y los modelos de sociedad que sostienen los actores políticos y sociales.

En definitiva, de lo que se trata es de analizar las manifestaciones discursivas de distintos actores políticos y sociales de Argentina, con el fin de interpretar qué entienden que es o debiera ser la ciudadanía, y los posibles conflictos entre éstos, en el marco de las elecciones legislativas de octubre de 2001.

\section{ACLARACIONES ACERCA DEL CONCEPTO DE CIUDADANÍA}

En principio es preciso señalar que lo que se entiende por ciudadanía y por ciudadano, ha variado a través de la historia y entre las distintas formaciones sociales, puesto que se trata de un concepto que se encuentra relacionado a las distintas formas de organización humana, y las mismas se transforman a lo largo del tiempo. En este sentido, distintos autores han señalado la importancia de pensar a la ciudadanía respecto a las condiciones políticas, económicas y sociales de cada organización social y a los actores concretos que intervienen en cada contexto (Andrenacci, 2001; Landau, 2003; Dubet, 2003; Svampa, 2004; Cullen, 2007).

La importancia de esta interpretación radica en que nos permite entender que la ciudadanía es una construcción histórico-social, y que si pretendemos desarrollar una interpretación acerca de la misma, deberemos enfocarnos en una sociedad determinada y estudiar cuáles son los modelos que los distintos actores políticos y sociales promueven acerca de la misma, y cuáles son las disputas que se producen entre estos actores. Por este motivo, las construcciones sociales acerca de la ciudadanía, no pueden analizarse independientemente de las condiciones históricas de una formación social determinada (Landau, 2006). Pensamos que las ideas de ciudadanía y de ciudadano se van formando y reformando al calor de los complejos procesos de estructuración social. En particular, en América Latina las concepciones y prácticas de la ciudadanía han recorrido un accidentado trayecto desde el siglo XIX hasta la actualidad; un trayecto que escasamente se homologa con aquél que Marshall indicara para las sociedades europeas (o acaso, solo para la inglesa), siguiendo sinuosos caminos, avances y retrocesos, en torno a las dimensiones civil, política y social del concepto (Escalante Gonzalbo, 1992; Murilo de Carvalho, 1995).

Por lo tanto, nos interesa indagar cómo dentro del complejo de relaciones que se establecen en la constitución de una formación social; tales como las relaciones de producción, la estructura de clases, la creación de instituciones jerarquizadas con funciones específicas, entre otras variables, el concepto, los atributos y las prácticas de lo que se denomina ciudadanía, se van constituyendo como un producto de los condicionamientos políticos, económicos y sociales de un periodo histórico determinado. Esto explica las grandes diferencias que existen entre lo que se entiende por ciudadanía en el presente y lo que se entendía por la misma en la antigüedad. 
En este sentido, compartimos la tesis de que las construcciones sociales acerca de la ciudadanía hacen referencia a ciertas prácticas discursivas y extradiscursivas que circulan constituyendo criterios de verdad acerca de lo que es y/o debería ser un buen ciudadano (Landau, 2003 y 2004). Consideramos, además, que la categoría ciudadanía es una herramienta pensable desde la defensa de un determinado modelo u organización de la sociedad. Desde esta óptica, la ciudadanía es una categoría fundamental, ya que se trata ni más ni menos que de establecer el estatus, el rol y los atributos que se les otorgan a los integrantes de la misma y, por lo tanto, es el objeto de una disputa entre los distintos actores políticos y sociales (Nun, 2001). En este orden de ideas, entendemos que las construcciones sociales acerca de la ciudadanía se expresan y, a la vez, se constituyen en el marco de procesos de disputa entre los distintos actores políticos y sociales, que pugnan por imponer sus propios modelos de ciudadanía, en contextos políticos, económicos y sociales determinados.

Ahora bien, las transformaciones económicas, políticas y sociales, que supuso la instauración del neoliberalismo a escala global, a partir de la década de 1970, influyeron en las construcciones sociales acerca de la ciudadanía. En todos lados se redefinieron los roles y las relaciones entre Estado y sociedad, y esto impactó sobre las formas ser y sentirse ciudadano (García Delgado, 1994; Rose, 1997; Svampa, 2004). Por este motivo, distintos autores han planteado la necesidad de pensar las características que asumió la ciudadanía en la Argentina contemporánea (Landau, 2003, 2004 y 2006; Svampa, 2004 y 2005; Cullen, 2007).

En nuestro caso, consideramos importante indagar los modelos de ciudadanía que se expresaron y/o promovieron en el contexto de crisis socio-política que se desarrolló en Argentina en el año 2001 y, en particular, en el marco del fenómeno del "voto bronca".

\section{LOS CAMINOS DE LA CIUDADANÍA HASTA LA CRISIS ARGENTINA DE 2001}

A partir de la década de los setenta se producen grandes transformaciones a nivel mundial, que están relacionadas con la crisis económica internacional y la crisis del Estado de bienestar, y que, por supuesto, tienen influencia sobre la Argentina. En nuestro país, sobre finales de la década de los ochenta se produce el cierre de una etapa, que creemos está vinculado con un modelo de Estado benefactor que resultó agotado, y que había empezado a modificarse a partir de la crisis en la que se encontraba sumido desde el tercer gobierno peronista (1973-1976). En este contexto, se produjo el auge del modelo neoliberal en Argentina, que va a producir grandes transformaciones en las relaciones entre Estado, sociedad y mercado.

Como resultado de estas transformaciones, a partir de la década del noventa, se modifican las concepciones acerca de la ciudadanía. Surgen otras manifestaciones de la misma, posiblemente relacionadas, por un lado, a la derrota política que significó para vastos sectores de la sociedad la imposibilidad de pensar en un mundo no capitalista y, por otro lado, con el 
consiguiente avance del pensamiento neoliberal con su confianza ciega en el mercado y el desprestigio de la acción del Estado.

Así Landau sostiene que "...a partir de lo que son las transformaciones de la década del '70 y, fundamentalmente a partir del año 1990 esa idea de ciudadanía, pensar en un modelo social, un modelo de integración, un modelo de reconocimiento de la solidaridad, no en términos caritativos, sino en términos de reconocimiento de interdependencias y de lo que debía ser el Estado para ellos, fue dejado de lado por un modelo individualista, por un modelo de ciudadanía consumista o ciudadanía de un modelo participativo pero muy fragmentario, de fragmentación del espacio social y urbano."3

Creemos que durante la década del noventa y, vinculado a la desaparición del rol de Estado y a la creciente fragmentación social, junto con las antiguas nociones de ciudadano, conviven otras concepciones, que se expresan en variados actores y que buscan legitimarse en la sociedad.

Ideas como la necesidad de achicar un Estado que estaría sobredimensionado y confiarle sus funciones a sectores económicos que resultarían más eficientes, planteamientos individualistas que venían desde tiempo atrás como el "sálvese el que pueda", el "no te metás", y el conocido "algo habrán hecho"; y el gran desprestigio en el que va a quedar la actividad política, debido a la corrupción de sus actores pero también a la instalación de la idea de que la política es "sucia" y patrimonio de "los políticos", van a configurar este cuadro de situación que respecto a la ciudadanía implicará que ésta encuentre otras expresiones muy variadas como la participación en pequeñas organizaciones no gubernamentales (ONG'S), aparentemente más probas y eficientes; la resignación ante este presente y a lo sumo la participación a través del voto, el escepticismo y, también, algunos sectores que resistiéndose a este modelo plantearon la necesidad de un pensamiento y una solución colectiva (en muchos casos con mecanismos de autogestión comunitaria para paliar la crisis) para sus problemas y que configuraron movimientos sociales sobre fines de la década de los noventa.

Ahora bien, a partir de 1998 comienza en la Argentina una etapa económica recesiva y se profundizan los niveles de desocupación y de pobreza. Asimismo, existía desde tiempo atrás, una fuerte visión en la ciudadanía de que el gobierno nacional era corrupto. En las elecciones presidenciales de 1999 gran parte de los argentinos votaron, esperanzados en transformar esta realidad, a los candidatos de la Alianza, Fernando De la Rúa y Carlos Álvarez. Pero esta esperanza duró poco, ya que las medidas económicas del nuevo gobierno estuvieron centradas en el ajuste y el recorte de beneficios para los ciudadanos. Tampoco la corrupción había sido atacada, al punto de sancionarse una ley de flexibilización laboral en el Congreso, en medio de fuertes sospechas de sobornos, que concluyeron en la renuncia del vicepresidente de la nación, Carlos Álvarez. La desocupación y la pobreza siguieron creciendo sin parar, y se desembocó en las elecciones legislativas de 2001, en el marco de un gran descontento hacia el gobierno y hacia la política en general.

${ }^{3}$ (2006) LANDAU, Matías, "Ciudadanía y ciudadanía juvenil", Conferencia dictada en el marco del Programa de Transformaciones Curriculares, Materia Construcción de Ciudadanía, DGCyE, La Plata, Pág. 13. 


\section{EL FENÓMENO DEL "VOTO BRONCA", ALCANCES Y DIVERSAS INTERPRETACIONES}

En las elecciones legislativas de octubre de 2001, se produjo un fenómeno que algunos actores denominaron "voto bronca", cuya principal característica fue que una buena porción de los argentinos, decidió no votar, anular su voto o votar en blanco. Según los cálculos posteriores, el $42 \%$ del padrón electoral no eligió a ningún candidato. Entre el ausentismo, los votos nulos y los votos en blanco, reunieron alrededor de 10,3 millones de personas. El ausentismo se elevó de $20,4 \%$ en 1997 y de 17,9\% en 1999 a alrededor del 25\% (6,1 millones de personas) en 2001. A su vez, los votos blancos y nulos tuvieron un promedio nacional del $22 \%$ (más de 4 millones de votos), cuando en las comicios de 1999 apenas habían alcanzado el 4,5\% de los votantes. Esto implicó que, en conjunto, los partidos políticos hayan perdido 4,4 millones de votos en relación a las elecciones previas (ver gráficos y tablas en el Anexo final).

Es decir, que en estas elecciones se produjo un hecho que fue sin lugar a dudas atípico, tanto en relación con las elecciones previas como a las posteriores. La mayor anomalía, en este sentido, estuvo dada por el crecimiento sideral del voto anulado. Esta forma de expresión estuvo precedida por una fuerte campaña en algunos medios de comunicación, así como por la militancia activa de la misma de parte de grupos de personas confeccionando y repartiendo boletas inválidas para los comicios.

Las reacciones ante esta campaña, y posteriormente ante esta expresión del electorado fueron disímiles y muy variadas. Desde algunos sectores se censuró esta metodología acusándola de escasa responsabilidad "cívica" y de atentar contra el sistema representativo. Asimismo, desde otros polos se lo interpretó como la expresión del malestar con el gobierno de la Alianza o con el conjunto de la "clase política" y los partidos políticos. En este caso se colocaba el foco del problema, o bien en el malestar por la crisis económica y social, o bien en el rechazo a una forma de hacer política y la corrupción de sus actores. Por último, algunos sectores valoraron esta dinámica por considerarla una forma válida de protesta frente a las decepciones causadas por experiencias como la de la Alianza y la sensación de impotencia sin alternativas reales ante la grave crisis que atravesaba el país.

En este contexto, podemos visualizar a través de los medios de comunicación la emergencia de sentidos diversos y contradictorios acerca de la ciudadanía que tienen como finalidad entender, interpretar 0 bien intervenir en este fenómeno del "voto bronca". Desde semanas previas a las elecciones del 14 de octubre los periódicos analizados (Clarín y La Nación) dedicaron páginas en las que daban cuenta de esta situación mediante encuestas o bien se formulaban consideraciones en columnas de opinión.

En concreto ya el 7 de octubre de 2001 en la edición del diario Clarín en nota titulada "Según la Iglesia, votar es una obligación moral" se expresa:

«Una alta fuente eclesiástica apeló a la elocuencia al ser consultada esta semana por Clarín sobre el fenómeno del voto bronca. "El voto nulo es descreer del sistema y considerar que no hay persona que lo pueda mejorar", dijo. [...] - ¿Pero no podría interpretarse el voto nulo o en blanco como una forma de protesta, digamos, por única vez?-, preguntó el cronista. -Podría 
interpretarse de esa manera, pero el país no se arregla protestando... ¿cambiará algo esta protesta?-, respondió el vocero...» (Clarín, 7/10/2001, pág. 4)

Estas consideraciones reflejan no solo el rechazo al "voto bronca" de parte de un actor social y político importante como es la Iglesia católica, sino que implica además una determinada idea de la ciudadanía. En este caso, se entiende que la ciudadanía se ejerce votando y haciéndolo en forma positiva. Se privilegia esta forma de participación en desmedro de otras, y sobre todo se censura la protesta. No va a tratarse del único actor que exprese este tipo de pensamiento. Coincidentemente otros actores van a plantear que el voto es el "instrumento ciudadano", identificando al ciudadano con la idea de votante, y desdeñando otras formas de participación. En este sentido, se entiende que el rol que tiene el ciudadano en la política es "elegir" entre las opciones que se le presentan y, secundariamente, participar en los partidos políticos. Así, Clarín plantea en una de sus editoriales:

«Los partidos políticos son las instituciones a través de las cuales la gente expresa sus voluntades y elige sus representantes en los diferentes niveles de gobierno. [...] En suma, cuando la protesta toma la forma de un distanciamiento de la vida política, cuando se abandona la posibilidad de construir fuerzas políticas que compitan por el voto popular o no se ejerce la potestad de elegir entre las opciones existentes, se profundizan los males que ocasionan el malestar...» (Clarín, 14/10/2001, Editorial pág. 32)

Más adelante analizaremos esta idea de "gente", pero interesa destacar que todo el planteo de posible participación ciudadana gira alrededor del voto, bien en forma directa, bien bajo la forma de "competir" por el voto popular.

Otro ejemplo de este tipo de pensamiento podemos verlo en el siguiente fragmento:

«No olvidemos una certidumbre. Es imprescindible para ejercer con plenitud nuestra responsabilidad ciudadana: cada persona es un voto, cada uno de nosotros somos un voto. $Y$ a todos nos iguala el acto de votar. Un voto es una herramienta de cambio, no es un arma para el verdugueo ideológico...» (Clarín, 11/10/2001, Opinión, Osvaldo Pepe, pág. 25)

En el mismo orden de ideas podemos leer los siguientes extractos de La Nación:

«Por otra parte, el voto no es solo un derecho. Es también un deber institucional, al concurrir a las urnas, el ciudadano desempeña una función que le ha sido encomendada por la Constitución: la de poner en marcha las instituciones democráticas, contribuyendo a posibilitar la integración de los órganos de gobierno de la República. [...] Pero es verdad también que el voto sigue siendo el gran instrumento que el ciudadano tiene a su alcance para cambiar los escenarios desfavorables, mejorar las instituciones y avanzar hacia la construcción de un futuro mejor...» (La Nación, 7/10/2001, Editorial, pág. 24)

«Frente a semejante panorama, quienes alientan para el domingo los votos en blanco, impugnados o anulados, los que creen que poniendo un San Martín dentro del sobre castigan a los políticos, de alguna manera se colocan a la altura de aquellos a los que quieren castigar, y terminan eludiendo la responsabilidad cívica de votar con responsabilidad. Que es elegir, al mejor o al 
menos malo, pero elegir y elegir, hasta que los buenos lleguen en algún momento...» (La Nación, 10/10/2001, Notas, Antonio De Turris pág.19)

Esta visión homogénea sostenida desde distintos actores lleva al autor de esta nota, que pertenece a la redacción de La Nación -refiriéndose al enojo con los representantes de los partidos políticos- a sostener:

«Y por más que nos enojemos con ellos cuando hacen mal las cosas, cuando piensan y se comportan mezquinamente, no hay otra vía para echarlos que la del voto...» (La Nación, 10/10/2001, Notas, Antonio De Turris pág.19)

Estas afirmaciones van a ser desmentidas meses después cuando fueron "echados" varios políticos de sus cargos (nos referimos a las renuncias del Ministro de Economía Domingo Cavallo, el Presidente de la Nación Fernando de la Rúa, el Presidente de la Nación electo por el Congreso Adolfo Rodríguez Saá, entre otras renuncias en medio de protestas sociales, piquetes y cacerolazos) sin mediar ninguna elección ni voto. Con lo cual podríamos pensar que en el marco de la crisis de 2001 el voto no fue ni el único, ni siquiera el más privilegiado medio de participación ciudadana, como sostienen algunos actores.

Ahora bien, también podemos encontrar en estos periódicos (aunque en forma marginal) críticas a estos modelos de entender la ciudadanía. Un ejemplo son las afirmaciones de Luis Zamora que sostuvo:

«Es hora de rebeldías ante un régimen político basado en pedir votos cada dos años y repartir ajustes y frustraciones todos los días...) (Clarín, 10/10/2001, pág. 36)

En este caso, se rescata al voto bronca como una forma válida de protesta y de participación ciudadana. Los siguientes son extractos de opinión de dos intelectuales que entienden en forma similar al voto bronca:

«Para Benbenaste, la conducta esperada del electorado se trata de una protesta cívica muy válida, que los políticos deberían valorar. "La ciudadanía les está diciendo algo así como: Ustedes nos usan para legalizar el instrumento electoral y decir que vivimos en democracia. Pero el instrumento no es condición suficiente de la democracia, porque lo están usando con fines no democráticos"...» (La Nación, 13/10/2001, Ciencia y Salud, Entrevista Narciso Benbenaste, pág. 16)

«Atilio Borón, profesor de Teoría Política de la Universidad de Buenos Aires y secretario ejecutivo de Flacso, consideró que el aumento de los sufragios negativos es "un mensaje muy claro para el gobierno, en particular, y para la clase política, en general, porque refleja una decepción y un desencanto muy grande del ciudadano con el juego democrático"...» (La Nación, 15/10/2001, pág. 12)

En el mismo sentido podemos ver las siguientes afirmaciones de María Eugenia Estenssoro:

«Los analistas dicen que representamos el voto negativo. Yo creo que el nuestro fue un voto positivo, comprometido que llama a la reflexión y expresa el deseo de mucha gente de no convalidar una forma de hacer política, frívola, irresponsable, que está llevando a la Argentina a la quiebra institucional, social y económica. [...] El 14 de octubre 10 millones de argentinos dijimos ¡basta!, 
queremos un país posible, positivo, con esperanzas. ¿Fue un voto bronca o un voto lúcido? [...] Diez millones de votantes sobre un total de 25, a quienes nos importa el país, pedimos un cambio. ¿Nos escucharán?...» (La Nación, 24/10/2001, Opinión, pág. 9)

Interesa destacar que en estos casos, al contrario de los señalados anteriormente, se entiende al voto bronca como una forma de cumplimiento del "deber cívico", y no se acota el rol del ciudadano al de mero elector. Por el contrario, pareciera otorgársele un rol más crítico y de intervención en la realidad por distintas vías según las circunstancias particulares de cada situación, en este caso a través del "voto bronca".

Ahora bien, vinculada a esta idea del ciudadano como votante, se encuentra presente una categorización de los ciudadanos muy fuerte de parte de una buena cantidad de actores. Esto es, se conceptualiza a la ciudadanía como "común". Es decir, existirían "ciudadanos comunes" y "ciudadanos no comunes".

La noción de ciudadano común aparece homologada a otras categorizaciones. Estas son, "ciudadano de a pie", "la gente", la población", etc. Son múltiples los discursos en los que aparecen estas nociones pero a modo de ejemplo podemos citar:

«Los asuntos externos son ajenos a la agenda del ciudadano común -dice Graciela Römer, politicóloga, en un diálogo con La Nación-...» (La Nación, 4/10/2001, Política, pág. 8)

«Si el lector está enojado con la que se denomina habitualmente "clase política", que en realidad es una suerte de partidocracia, tiene toda la razón del mundo y no se equivoca en su indignación. Pero debería considerar también que algunos ciudadanos comunes experimentamos, desde hace algunos años, parejos sentimientos y decidimos el arduo camino de empezar a hacer política, con la sana intención de ir abriendo camino para que otros ciudadanos comunes, iguales o mejores que nosotros, puedan sumarse para arreglar este berenjenal desde dentro de la democracia y sin violentar los principios republicanos...» (La Nación, 10/10/2001, Notas, Néstor Cruces, pág. 19)

«Habrá, en consecuencia, que proceder de tal modo que la ciudadanía pueda comprobar hasta qué punto, al velar por las instituciones de la República e identificarse con ellas, vela por su propia integridad. Porque eso es lo que la gente quiere. Eso, lo que más necesita. Reconocerse en la orientación que a los hechos imprimen las instituciones del país. Sentirse representada...» (La Nación, 14/10/2001, Santiago Kovadloff, pág. 13)

«Desilusionados con la Alianza, en estado de "bronca" y no sabiendo aún a qué atenerse respecto del justicialismo, los argentinos dieron lugar, el último domingo, a un voto "desconcertado". De ahí que las interpretaciones sobre el mensaje que envió en las urnas difieran tanto. Desde el momento en que el sistema político no le presentó a la gente una opción clara, era imposible que ella saliera mágicamente del escrutinio...» (La Nación, 21/10/2001, Notas, Mariano Grondona, pág. 29)

«Tal vez los gobernadores del PJ deberían recapacitar y comprender que la población, los ahorristas, los ciudadanos de a pie no necesitan una marcha federal, sino una dosis de sensatez que tal vez hasta sea premiado en los 
próximos comicios...» (La Nación, 30/10/2001, Jorge Oviedo, Economía Pág. 2)

Estas nociones, que son recurrentes en los discursos de muchos actores, nos permiten pensar que existirían dos tipos de ciudadanos. Por un lado, estarían los "ciudadanos comunes", la "gente", cuyo rol es votar, apoyar a un candidato $y$, en todo caso, si están en desacuerdo con las políticas que se llevan a cabo, esperar hasta la próxima elección para votar a otro candidato.

Relacionada a esta visión del ciudadano votante, podemos identificar también dentro de algunos referentes del peronismo, la idea de que la función del "pueblo" es apoyar o acompañar. Esto presupone una conducción que sería la que toma las decisiones, y una ciudadanía que acompaña, fundamentalmente, con el voto. Así, por ejemplo, en nota titulada "Ruckauf salió a pedir el voto para Duhalde" podemos leer:

«Le queremos pedir a cada hombre y mujer de la provincia de Buenos Aires que nos responda acompañando con su voto a Duhalde y a todos los que van en la lista del justicialismo...» (Clarín, 6/10/2001, pág. 12)

En el mismo tono un periodista de la redacción de La Nación señala:

«La ciudadanía espera y necesita la reactivación, el crecimiento, y mira angustiada todos los días que no pasa nada, que está todo quieto...» (La Nación, 28/10/2001, Jorge Oviedo, pág. 18)

Esta forma de entender a la ciudadanía parece una forma pasiva y limitada a determinadas funciones, que posiblemente proyecta una determinada manera de entender la organización social y que probablemente tenga como finalidad conservarla y reproducirla.

Por otro lado, correspondiente a estas ideas, tenemos aquellas que construyen la otra categoría, la de los otros ciudadanos, los "no comunes". Estos serían aquellos que se ocupan de la política, "la clase política", "los políticos". Un ejemplo de este discurso son los siguientes fragmentos:

«Si realmente queremos, como es necesario, revalorizar la política, afianzar el sistema de partidos, jerarquizar la misión de los dirigentes y gozar de prestigio social, los políticos debemos mejorar conceptos, usos y costumbres, así como el resto de la sociedad debe comprender que no es el mercado o la actuación de las corporaciones lo que hace más democrática una sociedad...» (La Nación, 4/10/2001, Alfredo Vítolo, pág.23)

«La ciudadanía tiene en claro que los políticos deberían comportarse de manera distinta. [...] Pero hoy, si los políticos quisieran, podrían rescatar la política y encontrarían un gran respaldo en la gente. La ciudadanía quiere realmente recuperar la política como territorio de lo público.» (La Nación, 1/10/2001, Ciencia y Salud, Entrevista Narciso Benbenaste, pág. 12)

Es decir, en estos discursos se les otorga la exclusividad de la política a "los políticos", en clara simetría con el rol otorgado al "ciudadano común".

En definitiva, podemos leer a través de estos discursos la construcción de modelos de ciudadano, que probablemente guarden relación con el carácter de los actores que sostienen estas nociones. Tanto desde la Iglesia católica, como de referentes de partidos políticos como el PJ y la Alianza, y de intelectuales de 
periódicos de circulación masiva como La Nación y Clarín, se sostienen ideas en muchos casos coincidentes en relación con el "voto bronca" y, más genéricamente, con el rol del ciudadano ante esta coyuntura.

\section{REFLEXIONES FINALES}

A modo de conclusión podemos señalar que, en el marco de esta investigación introductoria hemos podido identificar, dos tipos de posiciones respecto al "voto bronca", que creemos que proyectan dos maneras distintas de entender a la ciudadanía.

Estas son, por un lado, la de algunos actores encabezados por la Iglesia católica, los periódicos Clarín y La Nación, y algunos intelectuales y referentes de partidos políticos tradicionales como la Alianza y el PJ, que entienden al ciudadano mayormente como un votante que debe expresarse cada dos años, "eligiendo" entre las opciones que se le presentan. En este caso, rechazan otros medios de participación y/o protesta, como no sea votar, participar de estos partidos y, en el mejor de los casos, participar en organizaciones no gubernamentales. Este modelo es compatible con un rechazo al denominado "voto bronca" por entender que implica un incumplimiento del "deber cívico" y, asimismo, está correlacionado con una categorización de los ciudadanos entre aquellos que pertenecen a la clasificación de "comunes", y aquellos que se dedican a la "política".

Por otro lado, otro grupo de actores, fundamentalmente referentes de pequeños partidos políticos, que ocupan un lugar marginal en el discurso, evalúan en forma positiva el "voto bronca", interpretando que resulta una justa expresión de la ciudadanía ante la persistencia de la crisis y la falta de respuesta de la "clase política". En estas posiciones pareciera entenderse la ciudadanía desde una visión más amplia de sus roles, incluyendo además del voto, otras vías posibles de expresión para intervenir en la realidad.

A partir de estas conclusiones se disparan múltiples preguntas, tales como, ¿Qué relaciones podemos establecer entre los sentidos de ciudadanía que sostienen estos actores y los modelos de sociedad que defienden?, ¿De qué manera están correlacionados los modelos de sociedad que sostienen estos actores políticos y sociales con sus intereses vinculados al lugar que ocupan en la efectiva estructura económica y social de esta etapa histórica?, ¿Qué relaciones podemos establecer entre estos sentidos de la ciudadanía y las transformaciones económicas y sociales ocurridas en Argentina a partir de la década de 1990?, ¿De qué manera impactó el fenómeno del "voto bronca" en las prácticas asumidas por la ciudadanía sobre finales del 2001 y principios de 2002?

No corresponde responder todos estos interrogantes aquí, pero si reflexionar acerca de cómo pudo haberse proyectado el "voto bronca" tiempo después. Podemos entender que, independientemente de las interpretaciones que pudieran realizarse en cuanto a las motivaciones intrínsecas de las personas que participaron de este fenómeno, lo cierto es que se trató de un pedido de cambio respecto a la realidad que enfrentaba la Argentina. Ya sea referido a la corrupción, ya sea a la desocupación y la pobreza, ya sea al ajuste o a la 
recesión económica, lo cierto es que buena parte de la ciudadanía (un $42 \%$ del padrón electoral) eligió no votar a ningún candidato por entender que ninguno expresaba esta transformación reclamada.

Posiblemente, esta expresión forme parte de una serie que comenzó en 1997 y 1999 con los triunfos de la Alianza. Esto es así, puesto que la mayoría de quienes se volcaron a este fenómeno habían sido votantes de la misma, aunque el Partido Justicialista también perdió muchos votos. Si esto es como pensamos, esta serie continuó con las múltiples protestas que tuvieron uno de sus puntos cúlmines el 19 y 20 de diciembre de 2001.

Nuestra hipótesis es que, ante el fracaso de la "vía electoral", tanto en su faz "positiva" (voto a la Alianza), como en su faz "negativa" ("voto bronca"), una parte importante de la ciudadanía decidió adoptar otras formas de expresión para transformar la realidad que vivía, esto es, cacerolazos, marchas, piquetes, asambleas populares, etc.

Resulta llamativo que uno de los principales argumentos utilizados para desincentivar el "voto bronca" estuvo referido a que «aún sin votarlos terminás favoreciendo a la denominada "clase política" ", centralmente porque al no contabilizarse los votos negativos, se elevan los porcentajes de todos los partidos, con lo cual aumentan los cargos que se adjudican a cada lista. Esto implicó que, por ejemplo, el "gran ganador" de la jornada, el candidato a senador nacional por la provincia de Buenos Aires, Eduardo Duhalde, haya reunido oficialmente un 37,59\% de los votos positivos con 2.071.284 de votos, cuando en realidad estos votos, representaban apenas un 22,30 \% del total del padrón electoral de la provincia de Buenos Aires. Asimismo, en las elecciones de 1999 en las que había resultado perdidoso, en la Provincia de Buenos Aires había cosechado 2.738.524 de votos con lo cual en dos años perdió 667.240 "apoyos" (casi un $25 \%$ del total); y sumando el aporte de votos que en esa elección le hizo la U.CE.DE. sus guarismos ascienden a 3.115.966, en cuyo caso dilapidó 1.044 .682 votos (aproximadamente un 34\% del total). Igualmente, en 1997 su esposa Hilda Duhalde, había alcanzado como candidata a diputada nacional por la provincia de Buenos Aires, 2.846 .238 de votos, con lo que la merma de votos sería de 774.954 (más del $27 \%$ del total).

Es decir que, aún habiendo sido castigado en las urnas por buena parte de la ciudadanía, determinados actores políticos y sociales (como el propio Clarín) lo ungieron como el más fortalecido luego de las elecciones, a tal punto que incluso se incrementó la cantidad de bancas en el Congreso de su fuerza política. Es más, luego de esta tremenda manifestación se consolidó el predominio en el parlamento de las dos fuerzas políticas que la ciudadanía buscó castigar, la Alianza y el Partido Justicialista.

¿Qué consecuencias pudo haber tenido esta comprobación de parte de la ciudadanía?

Creemos que esta comprobación de que aún rechazándolos en la elecciones resultaron fortalecidos aquellos a quienes se quería rechazar, pudo haber tenido alguna influencia, en el entendimiento posterior de que el sistema político electoral argentino, no era el camino idóneo para transformar la realidad. Estas conclusiones pueden haber llevado a buena parte de la sociedad a encarar otras formas de participación y de intervención. Desde ya que las causas que desembocan en las jornadas de protesta del 19 y 20 de 
diciembre de 2001 son complejas y diversas, abarcando un contexto económico y social, entre otras variables significativas. Sin embargo, pensamos que no se debe despreciar el significado de esta experiencia del "voto bronca" para buena parte de la ciudadanía.

Si esto es como creemos, podremos comprender mejor por qué, en esta etapa histórica, se popularizan variadas formas de participación, como los piquetes, los cacerolazos, las marchas y las asambleas barriales. 


\section{ANEXO}

Tabla 1: Cantidad de ausentismo, votos en blanco y anulados en millones en elecciones nacionales de la República Argentina (1997-2007)

\begin{tabular}{|c|c|c|c|c|c|c|}
\hline 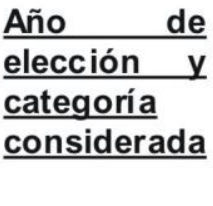 & $\begin{array}{l}\text { Total de } \\
\text { electores } \\
\underline{\text { hábiles }}\end{array}$ & $\begin{array}{l}\frac{\text { Cantidad }}{\text { de }} \\
\text { votantes }\end{array}$ & $\begin{array}{l}\text { Cantidad de } \\
\text { Ausentismo }\end{array}$ & $\begin{array}{l}\frac{\text { Cantidad }}{\text { de votos }} \\
\underline{\text { en }} \\
\underline{\text { blanco }}\end{array}$ & $\frac{\frac{\text { Cantidad }}{\text { de votos }}}{\text { anulados }}$ & $\begin{array}{l}\frac{\text { Sumatoria }}{\text { de votos }} \\
\frac{\text { en blanco }}{y} \\
\text { anulados }\end{array}$ \\
\hline $\begin{array}{l}1997 \\
\text { (Diputados) }\end{array}$ & 23.199 .814 & 18.472 .735 & 4.727 .079 & 958.673 & 262.216 & 1.220 .889 \\
\hline $\begin{array}{l}1999 \\
\text { (Presidente) }\end{array}$ & 24.111 .270 & 19.845 .855 & 4.265 .415 & 708.793 & 186.738 & 895.531 \\
\hline $\begin{array}{l}2001 \\
\text { (Senadores) }\end{array}$ & 24.907 .838 & 18.802 .968 & 6.104 .870 & 1.732 .861 & 2.519 .441 & 4.252 .302 \\
\hline $\begin{array}{l}2003 \\
\text { (Presidente) }\end{array}$ & 25.480 .440 & 19.930 .111 & 5.550 .329 & 196.574 & 345.642 & 542.216 \\
\hline $\begin{array}{l}2005 \\
\text { (Senadores } \\
\text { y/o } \\
\text { Diputados) }\end{array}$ & 26.140 .140 & 19.160 .145 & 6.979 .995 & 1.324 .209 & 463.307 & 1.787 .516 \\
\hline $\begin{array}{l}2007 \\
\text { (Presidente) }\end{array}$ & 27.137 .719 & 20.676 .655 & 6.461 .064 & 1.331 .010 & 241.176 & 1.572 .186 \\
\hline
\end{tabular}

Gráfico 1: Cantidad de ausentismo, votos en blanco $y$ anulados en millones en elecciones nacionales de la República Argentina (1997-2007)

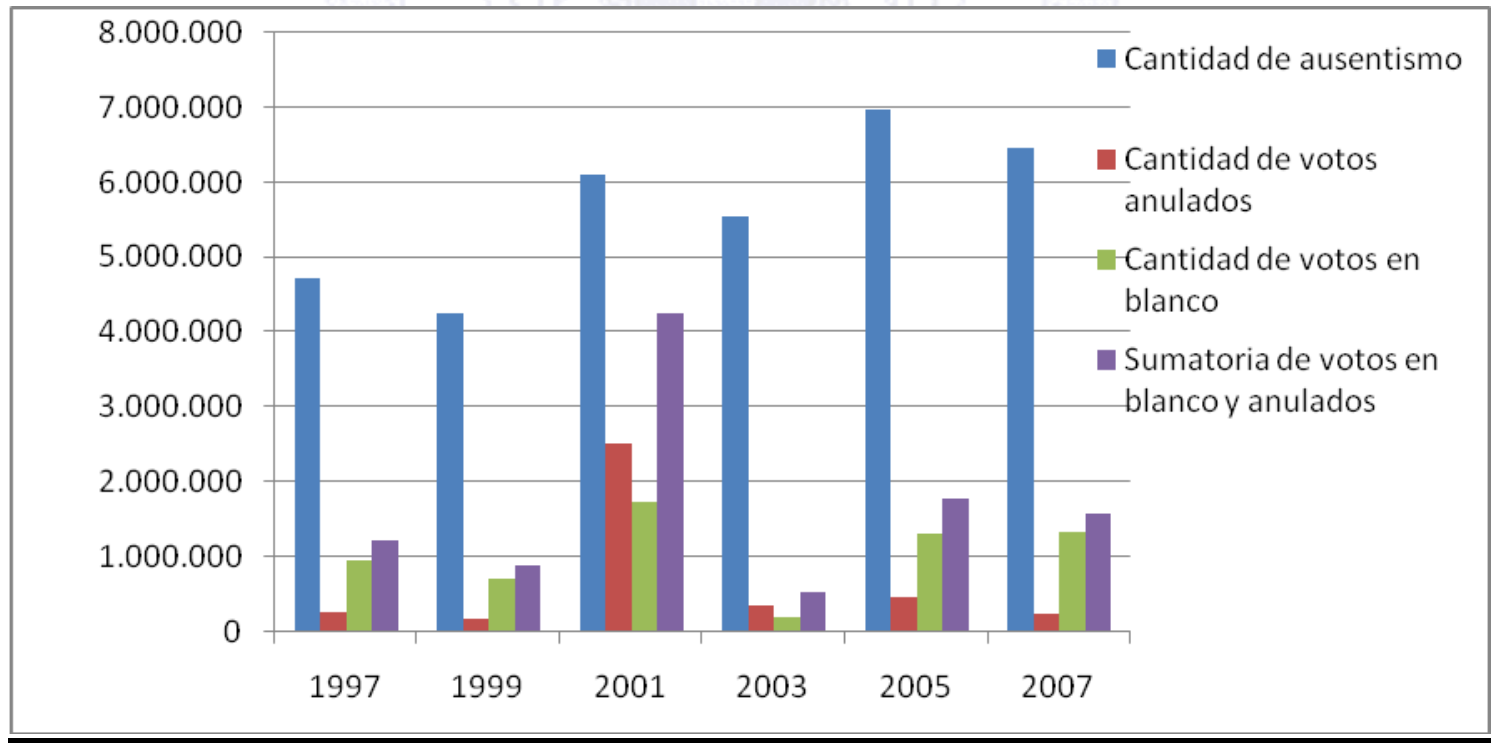

Tabla 2: Porcentajes de ausentismo, votos en blanco $y$ anulados en elecciones nacionales de la República Argentina (1997-2007) 


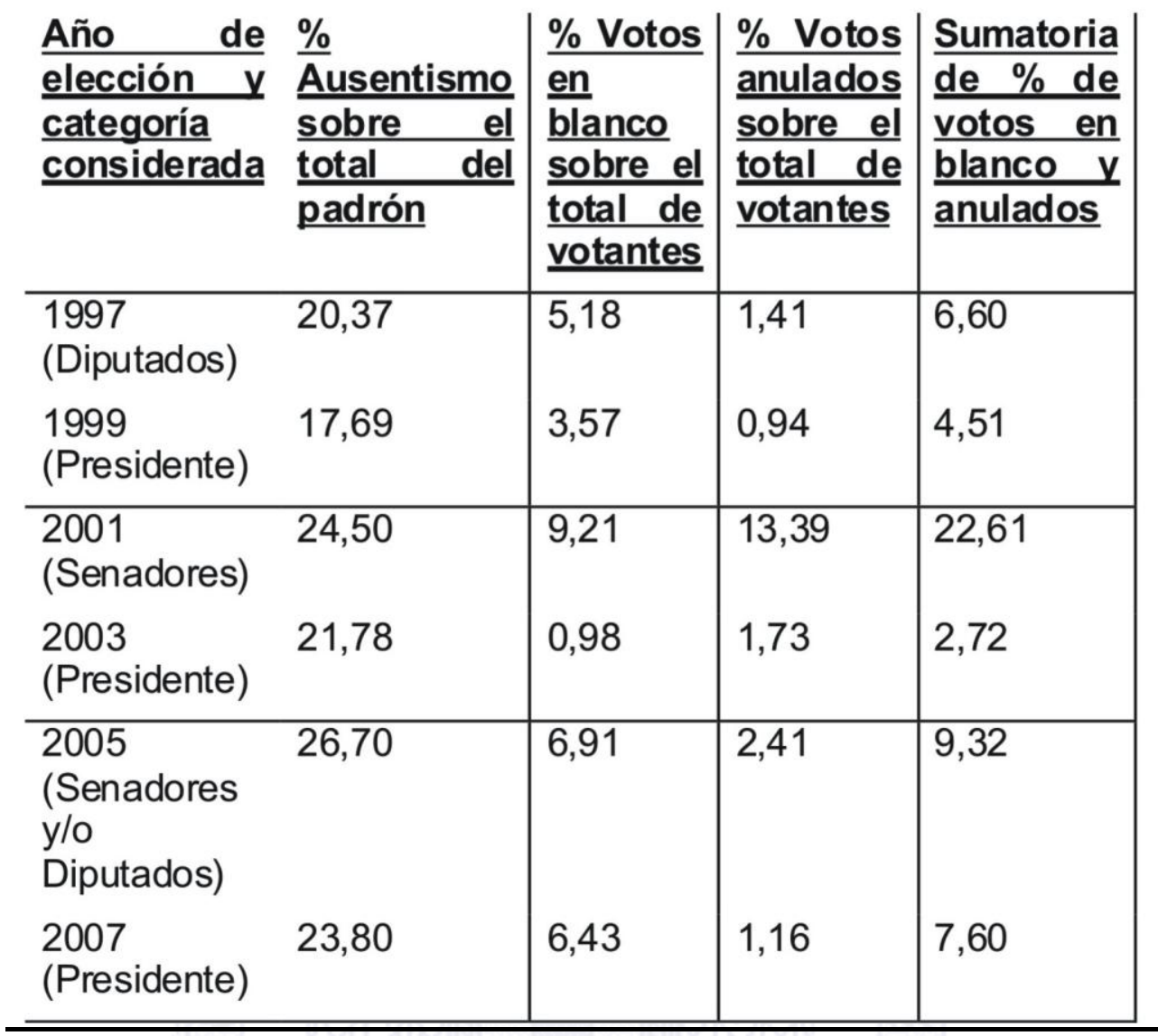

Gráfico 2: Porcentajes de ausentismo, votos en blanco $y$ anulados en elecciones nacionales de la República Argentina (1997-2007)

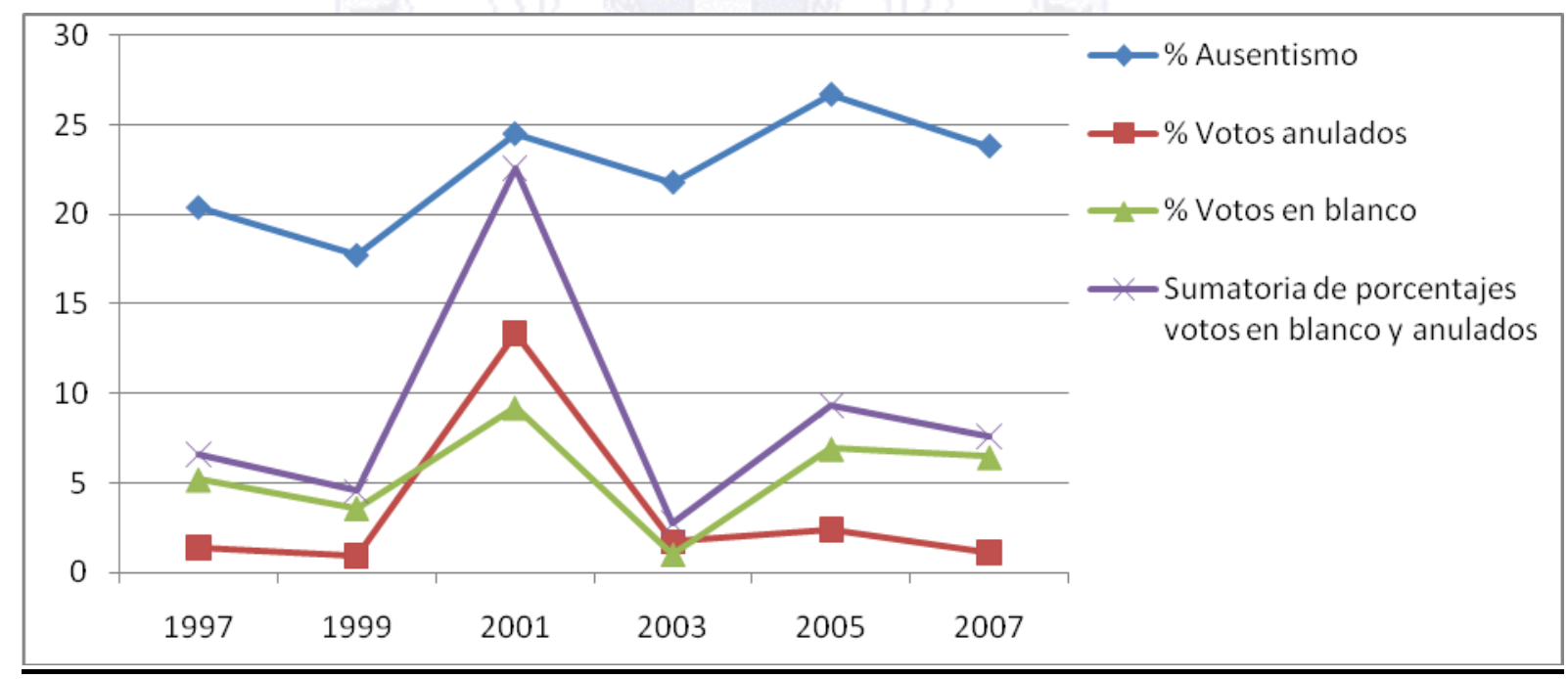

Fuente: Elaboración propia en base a datos extraídos de la Dirección Nacional electoral del Ministerio del Interior de la República Argentina. ${ }^{4}$

\footnotetext{
${ }^{4}$ Como criterio de recorte para poder contabilizar los votantes, los votos en blanco y los votos anulados en cada categoría, y en función de que en cada elección se elegían distintos cargos simultáneos, se optó por computar los votos en la categoría elegible que el sistema electoral
} 


\section{Referencias bibliográficas:}

\section{Libros:}

a) (1992) ESCALANTE GONZALBO, Fernando, Ciudadanos imaginarios, El Colegio de México, México.

b) (1992) FOUCAULT, Michel, Microfísica del poder, Editorial La piqueta, Madrid.

c) (1994) GARCIA DELGADO, Daniel R. Estado y sociedad. La nueva relación a partir del cambio estructural, Grupo Editorial Norma, Buenos Aires.

d) (1995) MURILO DE CARVALHO, José, Desenvolvimiento de la ciudadanía en Brasil. Fondo de Cultura Económica. México.

e) (1997) GARCÍA DELGADO, Daniel R. "Crisis de representación, nueva ciudadanía y fragmentación en la democracia argentina" en Mallo, Susana (comp.) Ciudadanía y democracia en el Cono Sur, Editorial Trazas, Montevideo.

f) (2001) NUN, José, Democracia ¿Gobierno del pueblo o gobierno de los políticos? Fondo de Cultura Económica, Buenos Aires.

g) (2003) ANDRENACCI, Luciano, "Ciudadanos en los márgenes de la modernidad. Buenos Aires, entre la colonia y la república", en Villavicencio, Susana (editora) Los contornos de la ciudadanía. Nacionales y extranjeros en la Argentina del centenario, Eudeba, Buenos Aires.

h) (2003) ANDRENACCI, Luciano, La ciudadanía como status desigual, Mimeo, Buenos Aires.

i) (2003) DUBET, François, "Mutaciones cruzadas: la ciudadanía y la escuela”, En Benedicto, J. y M. Morán (coord.), Aprendiendo a ser ciudadanos. Experiencias sociales y construcción de la ciudadanía entre los jóvenes, Instituto de la Juventud, Disponible en el área de descarga de www.injuve.mtas.es, Madrid

j) (2003) LANDAU, Matías, "Los múltiples significados de ser ciudadano. Ciudadanía y construcción de subjetividades en la Buenos Aires actual" en Murillo, Susana (coord.), Sujetos a la incertidumbre. Transformaciones sociales y construcción de subjetividad en la Buenos Aires actual, pp. 93-134, Centro Cultural de la Cooperación, Buenos Aires

k) (2004) LANDAU, Matías (coord.) Los discursos de la participación: Una mirada hacia la construcción de la figura del ciudadano en la prensa escrita de la Ciudad de Buenos Aires. Centro Cultural de la Cooperación. Buenos Aires.

argentino colocara en primer término. Por este medio en la confección de la boleta se coloca en primer término la fórmula presidencial, en segundo término los candidatos a senadores nacionales y en tercer término los candidatos a diputados nacionales. Puesto que en los distritos electorales se eligieron en cada caso distintas autoridades, se decidió medir el impacto en la categoría que se encontrara en primer término, por lo cual en las elecciones en las que se eligió presidente (1999-2003-2007) se contabilizó esta categoría, en las elecciones de 1997 solo se eligieron diputados nacionales, y en las elecciones de 2001 y 2005 se seleccionó según este criterio entre la categoría senadores nacionales y diputados nacionales en cada distrito electoral. 
I) (2005) SVAMPA, Maristella. La sociedad excluyente. La Argentina bajo el signo del neoliberalismo, Taurus, Buenos Aires.

m) (2007) CULLEN, Carlos A. (comp.) El malestar en la ciudadanía, Stella-La Crujía, Buenos Aires.

\section{Artículos:}

a) (1997) ROSE, Nikolas "El gobierno de las democracias liberales 'avanzadas': del liberalismo al neoliberalismo", en Archipiélago. Cuaderno de critica de la cultura 29, Buenos Aires.

b) (2001) ANDRENACCI, Luciano. "De Civitas Inaequalis. Elementos para una teoría de la ciudadanía", Ponencia presentada al № Congreso Nacional de Ciencia Política de la Sociedad Argentina de Análisis Político (SAAP), Universidad Nacional de Río Cuarto.

c) (2001) NUN, José, "Trabajo, ciudadanía y política", Conferencia $5^{\circ}$ Congreso Nacional de la Asociación Argentina de estudios del Trabajo, Disponible www.bazaramericano.com/bazar/articulos, Buenos Aires.

d) (2004) SVAMPA, Maristella, "Estado, democracia y proyecto de nación. Modelos de ciudadanía y actores sociales durante los noventa", Escenarios, Revista Institucional de la Escuela Superior de Trabajo Social, Año 4, №8, La Plata.

e) (2006) LANDAU, Matías, "Ciudadanía y ciudadanía juvenil", Conferencia dictada en el marco del Programa de Transformaciones Curriculares, Materia Construcción de Ciudadanía. DGCyE. La Plata.

* Abogado, Universidad Nacional de Mar del Plata. Docente de Construcción de la Ciudadanía y Derechos Humanos en escuelas del nivel medio de la ciudad de Mar del Plata. Miembro del "Grupo de Estudios Socio-Históricos y Políticos" (OCA 1593/2010) Facultad de Humanidades, Universidad Nacional de Mar del Plata. Email: agustinperisse@gmail.com 